\title{
Cambios de usos del suelo en la periferia del área metropolitana de Buenos Aires. Aportes para una teoría de la rent gap periurbana
}

\author{
Changes in land use in the periphery of Buenos Aires metropolitan area. \\ Contributions to a peri-urban rent gap theory
}

\author{
Ricardo Apaolaza \\ Instituto de Geografía "Romualdo Ardissone". \\ Facultad de Filosofía y Letras. Universidad de Buenos \\ Aires, Argentina \\ Juan Pablo Venturini \\ venturinijuanpablo@gmail.com \\ Instituto de Geografía "Romualdo Ardissone". \\ Facultad de Filosofía y Letras. Universidad de Buenos \\ Aires, Argentina
}

Recepción: 07 Octubre 2020

Aprobación: 08 Enero 2021

Publicación: 03 Mayo 2021

Cita sugerida: Apaolaza, R. y Venturini, J. P. (2021). Cambios de usos del suelo en la periferia del área metropolitana de Buenos Aires. Aportes para una teoría de la rent gap periurbana. Geograficando, 17(1), e087. https://doi.org/10.24215/2346898Xe087
Resumen: Desde mediados de la década del 1990 se observa una fuerte expansión de urbanizaciones cerradas en las periferias metropolitanas de Buenos Aires, que avanzan sobre áreas ambientalmente frágiles, como humedales y suelos deteriorados por actividades extractivas. El diferencial entre la renta real de estos suelos y la alta renta potencial vinculada al uso residencial para sectores de ingresos altos tiende a ser capturado como una ganancia extraordinaria, y representa por ende un fuerte estímulo para la (re)inversión de capital y el avance inmobiliario. A través de análisis satelital y geoestadístico, el presente trabajo problematiza algunas de estas dinámicas, valiéndose de la hipótesis de un ciclo de cambios secuenciados en el uso del suelo tendiente a conformar una brecha de renta periurbana (o peri rent gap), con lo que se traza un paralelismo con la conocida teoría de Neil Smith.

Palabras clave: Teoría de la rent gap, Renta del suelo periurbano, Urbanizaciones cerradas, Humedales, Actividad ladrillera.

\begin{abstract}
Since the mid-1990s, a strong expansion of gated communities has been observed in the metropolitan peripheries of Buenos Aires, advancing on environmentally fragile areas, such as wetlands and soils damaged by extractive activities. The difference between the real ground rent and the high potential ground rent associated with residential use for high-income sectors tends to be captured as an extraordinary profit, and thus represents a strong stimulus for capital (re)investment and real estate development. Through satellite and geostatistical analysis, the present article problematizes some of these dynamics, with the hypothesis of a cycle of sequenced changes in land use tending to form a peri-urban rent gap (or peri-rent gap), drawing a parallelism with the well-known theory by Neil Smith.
\end{abstract}

Keywords: Rent gap theory, Peri-urban ground rent, Gated communities, Wetlands, Brick production. 


\section{INTRODUCCIÓN}

Las periferias de las ciudades latinoamericanas han tendido a una creciente fragmentación y polarización socioeconómica observable incluso a pequeña escala, con Buenos Aires como un claro ejemplo de ello. La expansión urbana dispersa y en baja densidad protagonizada por sectores de ingresos altos se contrapone a la urbanización popular precaria mediante loteos irregulares y asentamientos informales. El correlato de estas formas espaciales divergentes es una apropiación y un reparto profundamente desigual de los costos y beneficios económicos, sociales y ambientales del proceso de urbanización. Con este escenario de fondo, el presente trabajo busca ayudar a entender algunas de las lógicas que guían los novedosos procesos de avanzada inmobiliaria sobre zonas que históricamente despertaron poco interés para los desarrolladores privados. Para ello se propone analizar y problematizar las secuencias de cambio de uso del suelo en las periferias urbanas por medio de la hipótesis de una brecha de renta periurbana, trazando un paralelismo con el esquema teórico-conceptual de la rent gap elaborado por Neil Smith para explicar procesos de gentrificación en áreas pericentrales (Smith, 1979, 2012).

Mientras que los procesos de gentrificación se ven estimulados por un desfasaje entre las rentas reales y potenciales del suelo en zonas pericentrales (rent gap), capturable como una sobre ganancia (Smith, 1979), los procesos de colonización inmobiliaria de las periferias encuentran su principal aliciente en la transformación del suelo rural a urbano. Más allá de este estímulo siempre presente, en las últimas décadas se detecta en la periferia metropolitana de Buenos Aires un novedoso componente adicional. Al analizar la expansión urbana generada por los recientes desarrollos inmobiliarios, aparece una particular tendencia al avance sobre dos zonas periféricas específicas: por un lado, humedales, es decir, terrenos bajos inundables de manera permanente o intermitente, y por otro, suelos degradados que han sido afectados por actividades extractivas, como ladrilleras o canteras. Se propone que esta particular preferencia de los desarrolladores inmobiliarios no sólo se explica por las inversiones estatales en materia de autopistas e infraestructuras (Ciccolella, 2014), el laissez faire de la normativa urbana (Clichevsky, 2003) y la constitución de regímenes urbanos de coalición y articulación público-privada (Stone, 1993, 2001), que en su conjunto permitieron la avanzada sobre estos terrenos particularmente frágiles, sino también por la posibilidad de captar un enorme diferencial de renta capaz de compensar con creces los evidentes mayores costos de acondicionamiento de estos terrenos previo a su fraccionamiento y comercialización.

Efectivamente, humedales y suelos “decapitados" por actividades extractivas (Morello y Rodríguez, 2001) son terrenos que se presentan como una depresión o valle en el gradiente de rentas rurales y, por lo tanto, con precios relativos muy bajos: ninguna actividad agrícola-ganadera o extractiva puede desarrollarse plenamente en tales zonas, sea por la ausencia del horizonte húmico o bien por el anegamiento o las inundaciones recurrentes. Por ende, ceteris paribus, la adquisición de esos suelos desvalorizados para dichas actividades primarias y su reconversión habilitan la captura de un diferencial de renta extraordinario, correspondiente con el paso de rural sin uso posible -o bien de bajísima intensidad- a urbano residencial de medio y alto estatus, algo que se denominará en este trabajo "brecha de renta periurbana" o peri rent gap.

Lo novedoso es que estas lógicas inmobiliarias no sólo tienen impactos negativos sobre las condiciones ambientales locales y regionales (Pintos y Narodowski, 2015), sino que adicionalmente tienden a entrar en tensión con otras lógicas, que se suelen llamar sociales o de la necesidad (Pírez, 2006), asociadas a la conformación de asentamientos populares, ya que éstos también han tendido a emplazarse sobre estos suelos periféricos degradados e inundables, justamente por tratarse de terrenos históricamente fuera de toda disputa. 


\section{Metodología}

La metodología está basada en el análisis satelital y geoestadístico de las áreas de expansión urbana reciente del Área Metropolitana de Buenos Aires (AMBA), ${ }^{1}$ con especial foco en un caso de escala municipal. El recorte temporal propuesto abordará las últimas dos décadas (i.e., 2001-2020), lo que se fundamenta no sólo en ser éste un período de particular auge de las urbanizaciones cerradas (Guevara, 2014; Lanfranchi et al., 2018), sino también en razones operativas, asociadas a la disponibilidad de imágenes satelitales de detalle. El alcance espacial se propone según dos niveles diferenciados de análisis: uno general, de escala metropolitana, cuyo recorte se operacionalizó como las franjas de expansión urbana año a año dentro del área metropolitana, entendiendo este último concepto en su sentido estricto (i.e., mosaico de áreas de gobierno sobre las cuales se extiende la mancha urbana, Pírez, 1994); y otro de escala local, correspondiente con el estudio de caso a nivel municipal, cuyo recorte se circunscribirá al partido de Esteban Echeverría.

Analíticamente, el trabajo se basó en la comparación de resultados obtenidos por procedimientos geoestadísticos, en los que se indagaron cambios secuenciados en el uso del suelo, con búsqueda de unidades parcelarias que pasasen de rural inundable o rural de suelo decapitado, a residencial en urbanizaciones cerradas y equipamiento asociado (canchas de golf, áreas parquizadas, etc.). Todo el proceso de reflexión analítica se desarrolla en diálogo con los ya mencionados postulados de Neil Smith.

\section{RESULTADOS Y DISCUSIÓN}

\section{Los cambios en las modalidades de expansión urbana del AMBA}

Desde inicios de la década de 1980, pero con fuerza durante la siguiente, la tradicional expansión urbana protagonizada por sectores populares mediante loteos o tomas de tierra (Torres, 1993) se fue viendo disputada por un nuevo patrón de expansión dispersa y fragmentada, protagonizado por sectores de altos ingresos y con las urbanizaciones cerradas y grandes equipamientos periféricos como elementos dominantes (Janoschka, 2002; Pírez, 2006).

Con posteridad a la crisis del 2001, la rama de la construcción (fundamentalmente de residencia privada) funcionó dentro del esquema neodesarrollista como uno de los principales campos de absorción del sobrante de trabajo y excedente de capital y dirigió buena parte de estas fuerzas hacia las periferias metropolitanas. La producción del espacio urbano continuó capitaneada por el mercado, ayudado por el accionar estatal tendiente a propiciar la valorización inmobiliaria. Esto no hizo más que profundizar las tendencias de la década anterior, con fuertes transferencias de renta al sector privado y la generación de periferias dispersas, de baja densidad, privatizadas y segregadas (Ciccolella, 2014; Guevara, 2014).

$\mathrm{Si}$ bien algunos estudios sobre expansión urbana popular en el AMBA durante la década de 2000 mostraron que la cantidad de nuevos loteos populares, asentamientos y barrios de vivienda social no era para nada despreciable (Apaolaza, 2016, 2018), lo cierto es que al analizar globalmente la superficie añadida a la urbe el predominio de las urbanizaciones cerradas resulta indiscutible. Es decir, que en términos espaciales, la expansión urbana estuvo protagonizada por las urbanizaciones cerradas. Por ejemplo, el Centro de Implementación de Políticas Públicas para la Equidad y el Crecimiento (CIPPEC) estudió la expansión de las grandes ciudades en Argentina entre 2006 y 2016 y constató que el $46 \%$ de la superficie añadida a la aglomeración Gran Buenos Aires en ese período correspondió a urbanizaciones cerradas, frente a un $14 \%$ de residencia informal y un $24 \%$ del resto de los usos residenciales (Lanfranchi et al., 2018).

El recuento realizado para el presente trabajo muestra que durante el período 2001-2020 se generaron al menos 168 nuevas urbanizaciones cerradas en las franjas de expansión de la segunda y tercera corona, con superficies del orden de las 13.940 hectáreas. De estas, un total de 62 urbanizaciones (es decir $37 \%$ ) 
se asentaron total o parcialmente sobre terrenos anteriormente ocupados por humedales, mientras que un total de 30 (es decir, $18 \%$ ) hicieron lo propio sobre suelos decapitados y terrenos anteriormente ocupados por actividad ladrillera artesanal u otras extractivas. ${ }^{2}$ En términos de superficie, esto representa valores del orden de las 6.132 ha de recambio de humedales y 673 ha de recambio de suelos decapitados. Cabe destacar que casi la mitad (49\%) de la nueva superficie destinada a urbanizaciones cerradas se implantó sobre alguno de estos dos tipos de suelo. La Figura 1 y la Tabla 1 permiten tener una rápida visión del panorama a escala metropolitana.

Tabla 1. Implantación de urbanizaciones cerradas sobre suelos decapitados y humedales, por municipio de la segunda y tercera corona del AMBA, en el período 2001-2020

\begin{tabular}{|c|c|c|c|c|c|c|c|c|c|c|c|}
\hline \multirow[t]{2}{*}{ Municipio* $^{\star}$} & \multicolumn{2}{|c|}{$\begin{array}{c}\text { Urbanizaciones } \\
\text { Cerradas } \\
2001-2020\end{array}$} & \multicolumn{3}{|c|}{ Sobre humedales } & \multicolumn{3}{|c|}{$\begin{array}{l}\text { Sobre suelos } \\
\text { decapitados }\end{array}$} & \multicolumn{3}{|c|}{ Ambos } \\
\hline & Número & ha & Número & ha & $\%$ & Número & ha & $\%$ & Número & ha & $\%$ \\
\hline \multicolumn{12}{|l|}{ Segunda corona } \\
\hline Almirante Brown & 2 & 26 & 0 & 0 & $0,0 \%$ & 1 & 2 & $7,0 \%$ & 1 & 2 & $7,0 \%$ \\
\hline Berazategui & 17 & 1.231 & 3 & 672 & $54,6 \%$ & 7 & 164 & $13,3 \%$ & 10 & 836 & $67,9 \%$ \\
\hline $\begin{array}{c}\text { Esteban } \\
\text { Echeverría }\end{array}$ & 16 & 572 & 1 & 23 & $4,0 \%$ & 11 & 293 & $51,2 \%$ & 12 & 316 & $55,2 \%$ \\
\hline Ezeiza & 15 & 1.573 & 3 & 65 & $4,2 \%$ & 3 & 35 & $2,2 \%$ & 6 & 101 & $6,4 \%$ \\
\hline Fco. Varela & 0 & 0 & 0 & 0 & - & 0 & 0 & - & 0 & 0 & - \\
\hline La Matanza & 0 & 0 & 0 & 0 & - & 0 & 0 & - & 0 & 0 & - \\
\hline Merlo & 0 & 0 & 0 & 0 & - & 0 & 0 & - & 0 & 0 & - \\
\hline Moreno & 6 & 86 & 0 & 0 & $0,0 \%$ & 0 & 0 & $0,0 \%$ & 0 & 0 & $0,0 \%$ \\
\hline Tigre & 30 & 2.112 & 20 & 1.758 & $83,3 \%$ & 0 & 0 & $0,0 \%$ & 20 & 1.758 & $83,3 \%$ \\
\hline $\begin{array}{c}\text { Total segunda } \\
\text { corona }\end{array}$ & 86 & 5.600 & 27 & 2.518 & $45,0 \%$ & 22 & 494 & $8,8 \%$ & 49 & 3.013 & $53,8 \%$ \\
\hline \multicolumn{12}{|l|}{ Tercera corona } \\
\hline Cañuelas & 8 & 697 & 3 & 32 & $4,6 \%$ & 0 & 0 & $0,0 \%$ & 3 & 32 & $4,6 \%$ \\
\hline Escobar & 19 & 2.506 & 17 & 1.839 & $73,4 \%$ & 0 & 0 & $0,0 \%$ & 17 & 1.839 & $73,4 \%$ \\
\hline Gral. Rodríguez & 3 & 293 & 0 & 0 & $0,0 \%$ & 1 & 4 & $1,5 \%$ & 1 & 4 & $1,5 \%$ \\
\hline Marcos Paz & 1 & 92 & 1 & 16 & $17,6 \%$ & 0 & 0 & $0,0 \%$ & 1 & 16 & $17,6 \%$ \\
\hline Pte. Perón & 11 & 1.123 & 3 & 392 & $34,9 \%$ & 2 & 94 & $8,4 \%$ & 5 & 486 & $43,3 \%$ \\
\hline Pilar & 32 & 2.615 & 6 & 1.014 & $38,8 \%$ & 5 & 80 & $3,1 \%$ & 11 & 1.094 & $41,9 \%$ \\
\hline San Vicente & 8 & 1.016 & 5 & 321 & $31,6 \%$ & 0 & 0 & $0,0 \%$ & 5 & 321 & $31,6 \%$ \\
\hline $\begin{array}{c}\text { Total tercera } \\
\text { corona }\end{array}$ & 82 & 8.342 & 35 & 3.614 & $43,3 \%$ & 8 & 178 & $2,1 \%$ & 43 & 3.792 & $45,5 \%$ \\
\hline $\begin{array}{c}\text { Total s egunda + } \\
\text { tercera corona }\end{array}$ & 168 & 13.940 & 62 & 6.132 & $44,0 \%$ & 30 & 673 & $4,8 \%$ & 92 & 6.805 & $48,8 \%$ \\
\hline
\end{tabular}

*Se analizaron sólo los municipios parcialmente afectados por el Aglomerado Gran Buenos Aires al año 2001. Fuente: Elaboración propia 
Figura 1. Implantación de urbanizaciones cerradas sobre suelos decapitados y humedales en la segunda y tercera corona del AMBA en el período 2001-2020 y localización del caso de estudio

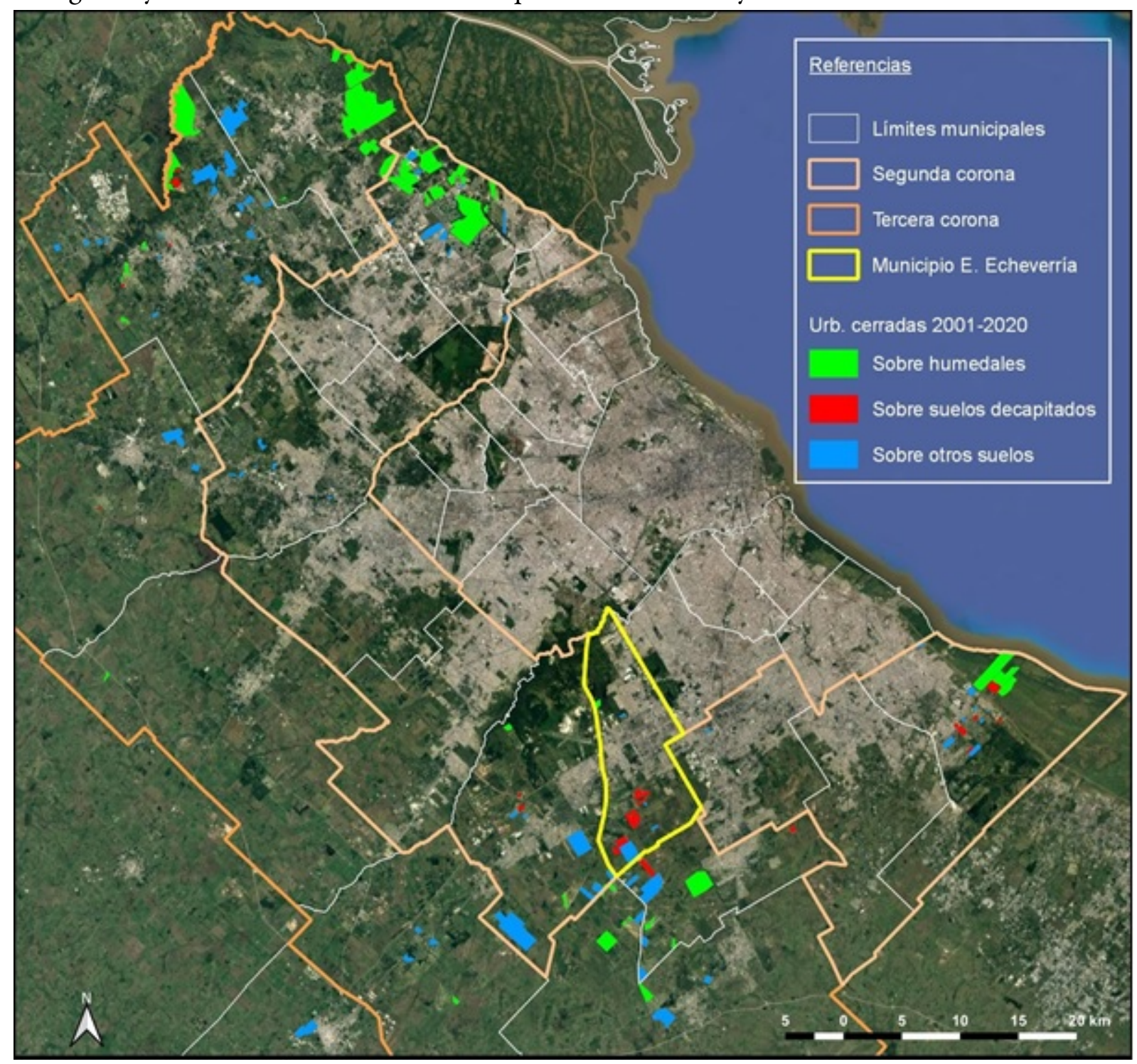

Fuente: Elaboración propia

Dentro de la tendencia general a nivel metropolitano, puede notarse la particularidad del municipio de Esteban Echeverría (ver Tabla 1 y Figura 1), donde el recambio de suelos decapitados adquiere un extraordinario peso. El análisis de ese caso, que se presenta a continuación, permitirá entender los ciclos de inversión y los dos tipos de brecha de renta vinculados a cada uno de estos tipos de suelo.

\section{La avanzada inmobiliaria en las periferias de Esteban Echeverría}

El municipio de Esteban Echeverría se ubica en la segunda corona del Área Metropolitana de Buenos Aires y es uno de los frentes de expansión de la aglomeración en dirección Sudoeste. Posee una forma más bien alargada en sentido Norte a Sur, con una superficie oficialmente estimada en 12.162 ha, de la cual aproximadamente la mitad estaba urbanizada para 2012 (Garay, 2012). Actualmente, la superficie urbanizada engloba algo más de 7.787 ha, es decir, aproximadamente un $64 \%$ del total municipal. Este proceso de fuerte expansión urbana se ve también reflejado con claridad en los altísimos niveles de 
crecimiento demográfico, con una población que pasó de 243.974 habitantes en 2001 a 300.959 habitantes en 2010 (INDEC, 2001, 2010), con estimaciones a 2020 de unos 371.000 habitantes (GPBA, 2016).

Históricamente, el proceso de expansión urbana dentro del municipio se organizó siguiendo el eje del Ferrocarril Gral. Roca, ramal Constitución - Ezeiza, que atraviesa de Este a Oeste el eje central del partido, dividiéndolo en dos mitades casi exactas. Sobre este mismo eje se constituyeron las centralidades tradicionales del distrito, Monte Grande (cabecera del partido), Luis Guillón y El Jagüel, y desde él se generaron franjas de expansión hacia uno y otro lado, que tempranamente se extendieron de manera compacta hasta las avenidas Fair/Valette al Norte y Dreyer/Suárez al Sur.

Las dinámicas de expansión urbana asociadas a barrios cerrados comenzaron a sentirse con fuerza desde mediados de la década de 1990 en la zona de Canning, ${ }^{3}$ en fuerte vinculación con las autopistas Ricchieri y Ezeiza-Cañuelas, y con la RP N ${ }^{\circ} 58$. Si bien existen algunos emprendimientos pioneros, como "Los Rosales" o "Allá en el Sur", el caso del barrio "Saint Thomas" suele tomarse como el kick off del boom inmobiliario del distrito. Esta primera oleada dejó un saldo de al menos 16 urbanizaciones cerradas dentro del municipio.

El recuento realizado para el presente trabajo muestra que las décadas de 2000 y 2010 fueron testigos de una nueva etapa de expansión, con un total de 14 nuevos barrios cerrados y 2 ampliaciones de barrios preexistentes, que incorporaron unas 572 ha al tejido residencial. Como se advirtió más arriba, la expansión de urbanizaciones cerradas sobre las zonas de humedal del municipio no resultó particularmente significativa (sólo un caso).

Por el contrario, resulta notable la avanzada sobre los suelos decapitados del Sur del municipio. Ya en relevamientos de principios de los años 1990 se marcaba que Esteban Echeverría era el municipio del AMBA con mayor superficie de suelos afectados por actividades extractivas, con 4.447 ha (Bozzano y Pintos, 1995, citado en Morello y Rodríguez, 2001). Relevamientos propios mediante imágenes satelitales de la franja de expansión Sur del municipio arrojaron para el año 20041.337 ha afectadas por extracciones de suelo principalmente por ladrilleras- sin nuevo uso, mientras que en 2019 esa superficie fue de 866 ha. ${ }^{4}$

Del total de 16 nuevas urbanizaciones cerradas o ampliaciones, 11 se asentaron total o parcialmente sobre suelos decapitados y terrenos anteriormente ocupados por actividad ladrillera artesanal u otras extractivas. Esto significa unas 293 ha de recambio de suelos decapitados por barrios cerrados, lo que representa el 51,2 $\%$ de la nueva superficie destinada a estos dentro del distrito. Esta tendencia de expansión sin duda se está viendo acompañada por las obras de extensión del Camino del Buen Ayre hasta la RP $\mathrm{N}^{\circ} 2$, actualmente en ejecución. Esta obra, al permitir una mayor accesibilidad, influye fuertemente sobre las tendencias de valorización inmobiliaria de la franja Sur de Esteban Echeverría, así como sobre sectores de Ezeiza, San Vicente y Presidente Perón.

Es pertinente mencionar que buena parte de estos terrenos decapitados, definidos como "neorrelieves", "neosuelos" y/o "neoecosistemas" por distintos estudios (Morello y Rodríguez, 2001; Garay, 2012), funcionan en la práctica como "neohumedales" que, a pesar de su importante degradación edáfica, cumplen una valiosa función ecológica y social, pues conservan islas de biodiversidad (avifauna, lutrinos y anfibios fundamentalmente), protegen zonas estratégicas de recarga de acuíferos de las nacientes y cuencas medias de los arroyos locales, y ayudan a la mitigación de las crecidas en todo el municipio.

\section{Hacia una teoría de la brecha de renta periurbana}

A lo largo de una serie de trabajos, Neil Smith $(1979,2012)$ desarrolló un corpus conceptual para abordar los procesos de gentrificación que se venían dando en las áreas centrales y pericentrales de las ciudades anglosajonas desde la década de 1950 y que se generalizaron durante la de 1970. Frente a las teorías por entonces dominantes, que priorizaban como factor explicativo las preferencias de consumo de los sectores 
medios y altos, Smith puso el foco en las lógicas de reinversión o "regreso" del capital a los centros urbanos, tras un largo período de movilidad de este hacia los suburbios.

En una primera instancia el autor detectaba una lenta pero sostenida baja de la tasa de ganancia inmobiliaria en los centros urbanos de las grandes ciudades de Estados Unidos, que ya había sido detectada por Hoyt (1933, citado en Smith, 1979) como una zona pericentral de clara depresión de los precios del suelo por metro cuadrado, lo cual se vinculaba directamente con el deterioro de la llamada zona en transición (Correa, 1993). Smith entendía esta baja en los precios como resultado de un proceso estructural de la economía capitalista urbana, en el que se combinaba el aumento del precio de los terrenos debido al aumento del cono de renta por el desarrollo urbano general con la progresiva desvalorización de las construcciones, asociada a su normal envejecimiento. Entonces, el capital fijo cristalizado en ciertas zonas como construcciones vetustas terminaba por constituir un obstáculo para el cambio de uso del suelo, y luego de décadas de abandono, se tendía a producir un valle en el gradiente de la renta real del suelo, que se profundizaba más y más debido a la falta de inversiones.

Se termina por identificar así un ciclo específico del capital, compuesto por cinco grandes fases: un primer momento de adquisición e inversión de capital sobre el terreno; un segundo momento de auge, cuando el precio de la vivienda todavía refleja su valor original, a la vez que la renta capitalizada aumenta debido al desarrollo urbano circundante; un tercer momento de decadencia asociada a la gradual e inevitable desvalorización de las construcciones, con una baja considerable en las rentas percibidas; tras la captura de ciertas rentas de agonía (e.g., alquileres a bajísimos precios para inmigrantes, instalación de actividades "no deseadas", etc.), se termina por entrar en un cuarto momento, en lo que Smith llamaba “colapso”, es decir, el abandono progresivo de las propiedades por no ser ya rentables; y quinto, cuando se llega al punto de máxima desvalorización y las propiedades se pueden comprar a un precio extremadamente bajo.

Este último representa el momento culminante del proceso de generación de la brecha de renta o rent gap, es decir, el desfasaje entre la renta real -i.e., capturada o capitalizada- del suelo, que viene decreciendo por la desvalorización del capital invertido, y la renta potencial asociada a posibles usos alternativos, la cual viene creciendo por el continuo desarrollo de la ciudad. El muy bajo precio de los terrenos y las posibilidades de grandes ganancias mediante su reconversión hacen que la reinversión de capital en estas áreas se vuelva sumamente rentable. Esta presión económica puede ser tan fuerte que el cambio en el tipo de uso (refuncionalización, verticalización, etc.) se torna inevitable. Luego de la reinversión y la comercialización, la renta potencial se realiza y el desarrollador, gracias a la captura o capitalización de la rent gap, obtiene una ganancia extraordinaria por sobre la tasa de ganancia normal de la rama de la promoción inmobiliaria.

Ahora bien, ¿es factible y provechoso repensar los recambios de usos del suelo detectados en el espacio periurbano del AMBA a partir de un paralelismo con la teoría de la rent gap de Neil Smith? La respuesta es sí. En un nivel general, tanto la gentrificación como la suburbanización -que en las últimas décadas se da en las periferias de las metrópolis latinoamericanas bajo el patrón de la urbanización dispersa o difusa- son arreglos o soluciones espacio-temporales llevados a cabo por el capital para superar barreras en el proceso de acumulación (Guevara, 2015). Como marca Smith (2012), lo que está en el centro de los procesos de gentrificación y suburbanización es la movilidad del capital hacia adentro y hacia afuera del entorno construido, respectivamente. En lo concreto, el esquema de Smith habilita la interpretación de al menos dos dinámicas estructurales con capacidad para generar desfasajes notables entre rentas reales y potenciales en el espacio periurbano, las cuales se desarrollan a continuación como peri rent gap tipo I y peri rent gap tipo II.

\section{Peri rent gap tipo I: Extractivas}

En la primera dinámica, el desfasaje aparece asociado a las actividades extractivas, en particular a la actividad ladrillera artesanal. Será denominado peri rent gap tipo $I$, ya que en este caso es posible un paralelismo casi total con los primeros planteos de Smith (1979). 
La actividad ladrillera artesanal tiende, por un lado, a alejarse de la ciudad construida porque requiere de grandes superficies de suelo fértil para desarrollarse y, en ese sentido, no puede competir con los usos urbanos. Por otro lado, la actividad tiende a estar cerca de la ciudad porque ésta -y en especial la ciudad en expansiónrepresenta su principal mercado y el costo de transporte tiene una alta incidencia sobre el valor del producto final, que se compone principalmente de materia prima con escaso valor añadido. El punto de equilibrio en esta tensión resulta en su emplazamiento, justamente, periurbano. Sin embargo, en un proceso conocido como "geofagia" (Morello y Rodríguez, 2001), la actividad ladrillera consume el horizonte superficial del suelo hasta agotarlo (“decapitación”), lo cual, sumado a la naturaleza permanentemente expansiva de la ciudad, lleva a que la actividad, lejos de mantenerse estática, tienda a desplazarse en acompañamiento del avance de la frontera urbana.

Esta dinámica dialéctica entre expansión urbana y ladrilleras termina por delinear también un ciclo de inicio, apogeo, decadencia y colapso a lo largo de los años, que finalmente habilita la posibilidad de una reinversión de capital:

- Inicio: cuando se adquieren los derechos sobre las tierras, y se inicia la extracción de los primeros horizontes del suelo dentro del predio.

- Auge: cuando la actividad ya se encuentra consolidada, con varias zonas de extracción dentro del predio y hornos en pleno funcionamiento, combinado con una disminución de los precios de fletes y aumento de la demanda, por el acercamiento de la frontera urbana debido a la expansión.

- Decadencia: cuando el predio comienza a agotar su disponibilidad de suelo fértil, y los ingresos percibidos tienden a mermar, debido a la necesidad de adquirir parte de la materia prima de manera externa. Aquí empiezan a generarse la caída de la renta real del suelo y el valle en el gradiente de rentas.

- Colapso: se produce cuando, tras un cierto período de extracción de rentas de agonía (en el cual el suelo se usa como soporte para la implantación de basurales, escombreras, estercoleras, chatarreras, etc.) y ya sin rentabilidad para continuar con la actividad ladrillera original, el predio es abandonado.

Al menos hasta mediados de la década de 1990, esta cuarta fase de los predios ladrilleros era la que típicamente ayudaba a viabilizar la persistencia de las tomas de tierras para asentamientos, ya que las motivaciones económicas de los dueños originales muchas veces no terminaban de justificar las costosas acciones legales de desalojo. Sin embargo, tras el auge de las nuevas modalidades de expansión urbana asociadas a los barrios cerrados, es posible comenzar a identificar la generación de una quinta fase en la que, al igual que en la dinámica de la gentrificación, aparece la adquisición de los terrenos a muy bajo costo para la reinversión de capital y la reconversión de los usos del suelo (alteo y nivelación, construcción de lagunas sobre las viejas cavas, tendido de redes, trazado de vialidades internas, loteo y edificación de viviendas), con la consecuente captura de la brecha de renta como una ganancia extraordinaria. En la Figura 2 se ilustra este proceso con un caso específico. 
Figura 2. Ciclo económico y reconversión de ladrillera artesanal en urbanización cerrada. Emprendimiento “Lagos de Canning” (3453’07” S, 58²8’35’ O), partido de Esteban Echeverría

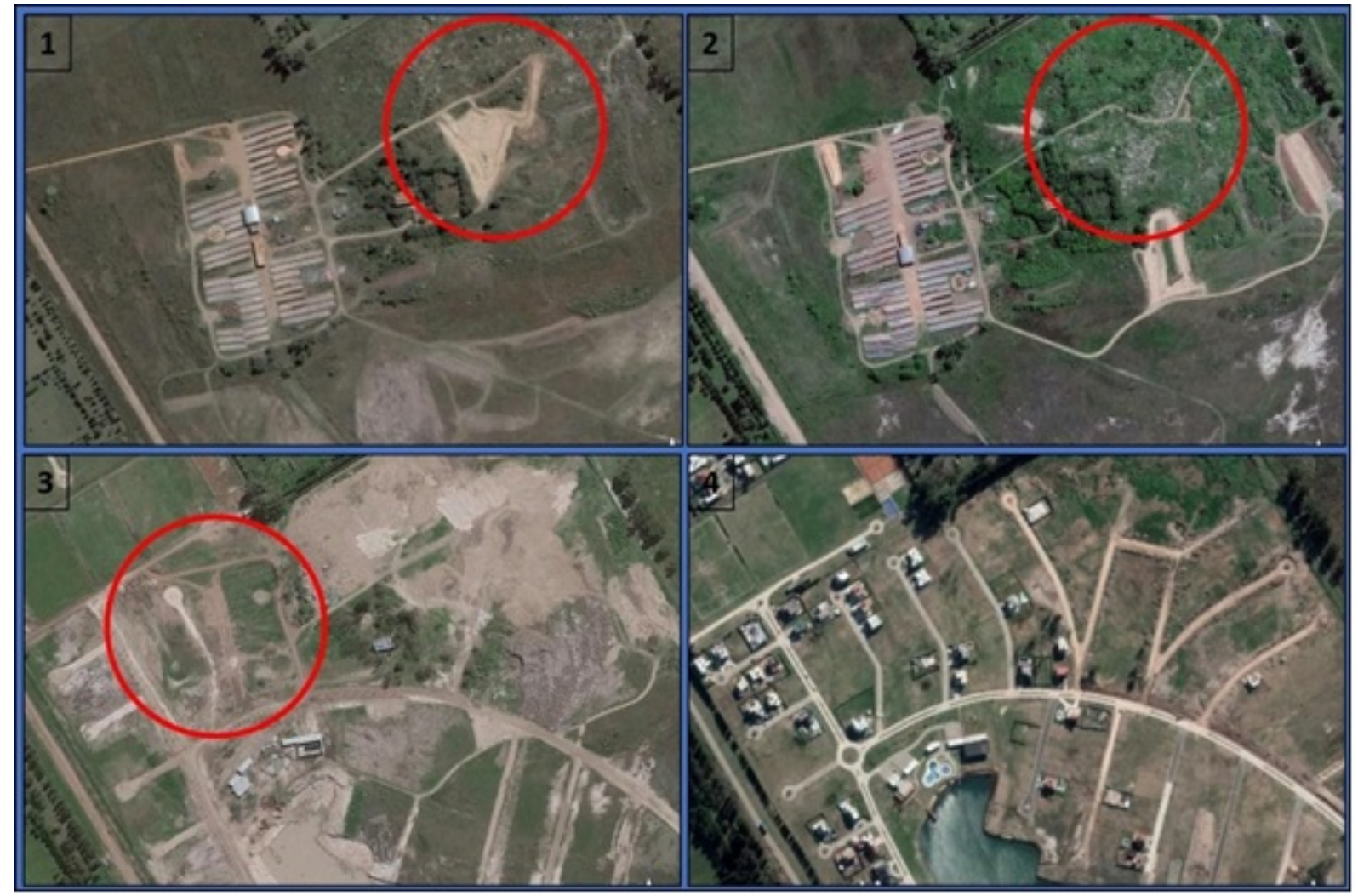

1) Año 2004. Auge: ladrillera en pleno funcionamiento. 2) Año 2010. Inicio de la decadencia: las zonas de extracción se han ido agotando y algunas son ofrecidas para la deposición de residuos (arriba a la derecha de la imagen). 3) Año 2012. Colapso e inicio de la reinversión: la actividad ladrillera ha sido totalmente abandonada y comienza a acondicionarse el predio para su urbanización. 4) Año 2019. Reconversión: para ese año ya se ven avanzados la venta y edificación de lotes, los espacios comunes y una laguna sobre viejas cavas. Fuente: Elaboración propia sobre la base de Google Earth

\section{Peri rent gap tipo II: Humedales}

Al igual que los suelos decapitados por actividades extractivas, las tierras ocupadas por humedales representan un valle en el gradiente de rentas rurales del suelo, pero con la particularidad de que esa depresión no se genera por una desvalorización producto de un ciclo económico, sino que está dada de antemano por las condiciones físico-naturales. Es decir, debido al anegamiento e inundaciones recurrentes no hay usos rurales que compitan por esos suelos, y si acaso se desarrolla agricultura o ganadería sobre ellos es en forma marginal, con muy baja intensidad. Además, la normativa ambiental y de zonificación de usos suele, al menos en principio, prohibir la urbanización de humedales, lo cual también contribuye a mantener muy bajo el precio relativo de estas tierras al dejarlas fuera de la dinámica de las rentas urbanas.

En un trabajo posterior a sus primeras formulaciones de la teoría, Smith (2012) introduce la posibilidad del desarrollo del rent gap sin la necesidad de una caída de la renta real del suelo sino solamente a partir de un fuerte aumento repentino de la renta potencial. En palabras del autor:

"Aquí nos hemos centrado en la situación general en la que un ciclo de desvalorización del capital, generado por la desinversión, es responsable del surgimiento de una brecha de renta. Pero también es posible concebir una situación en la que, en lugar de que la renta capitalizada del suelo sea empujada hacia abajo por la desvalorización, la renta potencial del suelo sea repentinamente empujada hacia arriba, abriendo de una forma diferente una brecha de renta. Éste podría ser el 
caso, por ejemplo, cuando [...] una regulación estricta del mercado de suelo mantiene baja la renta potencial del suelo, pero luego es repelida." (Smith, 2012, p. 126)

La desregulación (formal o real) del uso del suelo es justamente uno de los principales factores desencadenantes de la implantación de urbanizaciones cerradas sobre humedales del AMBA. Entonces, recuperando este ajuste en el marco teórico realizado por el mismo Smith, se denominará peri rent gap tipo II a la brecha de renta generada sobre humedales.

Para desarrollar este punto se retoma el trabajo de Pintos y Narodowski (2015) en la cuenca baja del Río Luján (municipios de Pilar, Campana, Escobar y Tigre). Antes que los factores puramente económicos, los autores remarcan la importancia de la alianza política entre el Estado y determinados grupos empresariales que permitió a estos últimos, desde fines de los años 1970, adquirir a muy bajo costo tierras bajas y humedales sobre los que no estaba permitido construir viviendas. Fue también la capacidad política de estos grupos para manipular la normativa a su favor, permitiendo los usos urbanos, lo que posteriormente les habilitó la captura de enormes brechas de renta.

En términos estrictamente económicos, Narodowski y Panigo (2015) muestran que no hay ninguna alternativa de uso del suelo sobre los humedales que pueda competir bajo las reglas del mercado con la rentabilidad del negocio inmobiliario. Los autores calculan una tasa interna de retorno en diez años de 566 $\%$, teniendo en cuenta la captura de la brecha de renta producto de haber adquirido el suelo a muy bajo precio. Se cierran así "los mejores negocios urbanos con los peores suelos" (Pintos y Narodowski, 2015: Prólogo de Ríos, p. 10), con ganancias que compensan con creces los costos de acondicionamiento de los terrenos para su urbanización. En términos ambientales, por un lado, los desarrolladores obtienen altas rentas diferenciales vinculadas a los atributos naturales y paisajísticos de estos entornos, pero, por otro lado, la urbanización implica un deterioro irreversible de ambientes y recursos naturales y una afectación de los servicios ecológicos que brindan los humedales, como la regulación hidrológica y el refugio de biodiversidad (Pintos y Narodowski, 2015).

En síntesis, la peri rent gap tipo II se genera a partir de terrenos históricamente ajenos a casi cualquier tipo de valorización económica por sus características desventajosas y/o por su función ambiental protegida, que son súbitamente puestos bajo el radar de la valorización inmobiliaria por un cambio radical en la normativa. Es decir, el eje aquí no está en un ciclo económico de desvalorización y caída de la renta real sino en una rezonificación -salvaje, pro mercado- que permite la realización de las altas rentas potenciales vinculadas a la expansión urbana de sectores ingresos altos, en lo que puede interpretarse como un abierto acto de vandalismo capitalista sobre los comunes urbanos.

\section{Recapitulación}

En la Tabla 2 se presenta una síntesis del paralelismo trazado entre la teoría del rent gap desarrollada por Smith $(1979,2012)$ y la propuesta del concepto de peri rent gap, con sus dos variantes y especificidades de cada caso en torno a algunos ejes fundamentales. 
Tabla 2. Ejes de la comparación entre la rent gap (Smith, 1979, 2012) y la peri rent gap

\begin{tabular}{|c|c|c|c|}
\hline \multirow[b]{2}{*}{ Variable } & \multirow[b]{2}{*}{$\begin{array}{c}\text { Rent gap (Smith, 1979, } \\
\text { 2012) }\end{array}$} & \multicolumn{2}{|c|}{ Peri rent gap } \\
\hline & & $\begin{array}{l}\text { Tipo I- Suelos } \\
\text { decapitados }\end{array}$ & $\begin{array}{c}\text { Tipo II - } \\
\text { Humedales }\end{array}$ \\
\hline Localización & Áreas pericentrales & \multicolumn{2}{|c|}{ Áreas periurbanas } \\
\hline Tipo de transición & $\begin{array}{l}\text { Zona en transición entre el } \\
\text { CBD y las áreas } \\
\text { residenciales }\end{array}$ & \multicolumn{2}{|c|}{ Transición urbano- rural } \\
\hline $\begin{array}{l}\text { Proceso socio- } \\
\text { espacial }\end{array}$ & $\begin{array}{l}\text { Gentrificación. Vuelta del } \\
\text { capital a la ciudad central }\end{array}$ & \multicolumn{2}{|c|}{$\begin{array}{c}\text { Suburbanización / urbanización dispersa. } \\
\text { Colonización de las periferias urbanas por el } \\
\text { capital }\end{array}$} \\
\hline $\begin{array}{l}\text { Rent gap: Caída de } \\
\text { la renta real y } \\
\text { formación del valle }\end{array}$ & $\begin{array}{l}\text { Cic lo de desvalorización de } \\
\text { construcciones por } \\
\text { desinversión }\end{array}$ & $\begin{array}{l}\text { Ciclo de desvalorización } \\
\text { por agotamiento del } \\
\text { horizonte superficial del } \\
\text { suelo }\end{array}$ & $\begin{array}{l}\text { Valle dado de } \\
\text { antemano por las } \\
\text { condiciones físico- } \\
\text { naturales }\end{array}$ \\
\hline Rentas de agonía & $\begin{array}{l}\text { Subdivisión y alquileres bajos } \\
\text { a inmigrantes, usos "no } \\
\text { deseados", etc. }\end{array}$ & $\begin{array}{l}\text { Implantación de basurales, } \\
\text { escombreras, estercoleras, } \\
\text { etc. }\end{array}$ & - \\
\hline $\begin{array}{l}\text { Rent gap: } \\
\text { Aumento de la } \\
\text { renta potencial }\end{array}$ & $\begin{array}{l}\text { Por desplazamiento del } \\
\text { "cono" de rentas debido al } \\
\text { desarrollo urbano general }\end{array}$ & $\begin{array}{l}\text { Por expansión urbana de } \\
\text { ingresos altos }\end{array}$ & $\begin{array}{l}\text { Por cambio de } \\
\text { normativa y } \\
\text { expansión urbana } \\
\text { de ingresos altos }\end{array}$ \\
\hline $\begin{array}{l}\text { Reinversión de } \\
\text { capital }\end{array}$ & $\begin{array}{l}\text { Renovación o rehabilitación } \\
\text { del medio construido }\end{array}$ & \multicolumn{2}{|c|}{$\begin{array}{l}\text { Acondicionamiento de los terrenos y producción } \\
\text { de nuevo suelo urbano }\end{array}$} \\
\hline $\begin{array}{l}\text { Cambio de uso del } \\
\text { suelo }\end{array}$ & $\begin{array}{l}\text { De vivienda/comercio de } \\
\text { sectores medio-bajos a } \\
\text { vivienda/comercio de } \\
\text { sectores medio-altos }\end{array}$ & $\begin{array}{l}\text { De suelos decapitados por } \\
\text { actividades extractivas a } \\
\text { vivienda de sectores de } \\
\text { ingresos altos }\end{array}$ & $\begin{array}{l}\text { De humedal a } \\
\text { vivienda de } \\
\text { sectores de } \\
\text { ingresos altos }\end{array}$ \\
\hline
\end{tabular}

Fuente: Elaboración propia

La cuestión principal a tener en cuenta son los mecanismos que operan en la formación de la brecha de renta en cada caso, para lo cual conviene diferenciar los dos procesos concomitantes señalados por Smith (1979): la formación del valle de renta y el aumento de la renta potencial. Con respecto al primero, en la peri rent gap tipo I la caída de la renta real del suelo no se produce por la desvalorización de un capital en forma de edificaciones, como sucede en la gentrificación, sino que se da por el deterioro del suelo en sí, que no sólo es el soporte del proceso productivo sino que también se consume como materia prima. Por su parte, en la peri rent gap tipo II no hay en verdad una depresión de una renta capitalizada del suelo, sino que el valle está dado desde un principio porque los terrenos ocupados por humedales, dadas sus características físico-naturales, nunca fueron medio ni objeto de valorización económica. De todas formas, en ambos casos el resultado son suelos que quedan fuera de la competencia para actividades rurales como la ganadería o la agricultura.

En cuanto a la renta potencial, Smith considera en principio su aumento gradual como producto del proceso normal de desarrollo y crecimiento de la ciudad, por el cual el gradiente o "cono" de renta se desplaza progresivamente "hacia afuera" y "hacia arriba" (Smith, 1979, p. 541). En las periferias el proceso fundamental que opera es la expansión urbana, en la que, al igual que en las áreas pericentrales gentrificadas, se observan desfasajes entre usos y rentas reales y potenciales, pero con la particularidad de que los mayores saltos relativos en el precio del suelo se registran en la transformación del suelo de rural a urbano (Jaramillo, 2009). Esos desfasajes se explican además por la yuxtaposición de "gradientes de rentas de la tierra que responden a lógicas de valorización urbana, industrial y agraria” (Bozzano, 1998, p. 4). Entonces, el aumento de la renta potencial puede ser más fuerte y no tan gradual como en las áreas pericentrales. Además, hay que tener en cuenta que se está analizando particularmente la expansión de sectores de ingresos altos mediante urbanizaciones cerradas, por lo cual las rentas urbanas potenciales son aún más altas que las esperables por el gradiente normal: las que Jaramillo (2009) llama rentas de monopolio de segregación, vinculadas a la posibilidad de vivir en entornos exclusivos. 
A partir de planteos posteriores de Smith (2012), surge el rol que puede tener en la brecha de renta un cambio en la normativa de usos del suelo al generar un fuerte aumento repentino de la renta potencial. Si bien se ha marcado que este es el proceso fundamental para entender la rent gap tipo II sobre humedales, es algo que puede suceder en cualquier zona de la ciudad, por ejemplo cuando se habilita el uso comercial en una zona hasta entonces residencial exclusiva o cuando se permite la construcción en altura en zonas bajas. También puede ser un factor importante para entender la valorización y urbanización de suelos decapitados por actividades extractivas que hasta entonces tuviesen una zonificación rural o alguna restricción de uso. De todas formas, cabe recordar que los cambios en la normativa no generan per se la valorización del suelo, sino que tienden a acompañar las tendencias estructurales del proceso de urbanización vinculadas a factores sociales, económicos y territoriales. 5

Hay interrogantes adicionales que podrían desarrollarse para profundizar y complejizar esta línea de análisis, pero por una cuestión de espacio sólo serán enunciados. Por ejemplo, ¿qué otros factores de desvalorización y valorización del suelo operan en concreto en la periferia metropolitana de Buenos Aires y cómo se relacionan entre sí (condiciones de sitio y de posición, obras públicas, cercanía de otros barrios cerrados o de asentamientos informales, entre otros) $?^{6}$ Otra cuestión es épor qué los desarrolladores pueden adquirir el suelo a un precio que no incorpora la renta potencial y qué papel pueden tener en ese sentido los comportamientos especulativos de los propietarios? (Smith, 2012). Esto llevaría a prestar mayor atención a las características sociales e institucionales específicas de los mercados de suelo en las áreas periféricas en comparación con otras áreas de la ciudad. Por último, se podría recurrir a autores como Jaramillo (2009) para pensar qué tipos de rentas urbanas (absoluta, diferencial tipo I y tipo II, de monopolio, etc.) componen el precio del suelo en cada momento del proceso que se ha estudiado.

\section{CONCLUSIONES}

En este trabajo se ha analizado la tendencia a la implantación de urbanizaciones cerradas en la periferia metropolitana de Buenos Aires sobre suelos desvalorizados, anteriormente ocupados por actividades extractivas y humedales. Se ha visto cómo esos cambios de uso del suelo reportan a los desarrolladores ganancias extraordinarias producto de la captura de una brecha de renta periurbana o peri rent gap, en sus dos variantes: tipo I y tipo II, respectivamente.

Smith (2012) destaca que un componente clave de la gentrificación es la construcción del mito de la frontera. Es interesante observar cómo esto también se replica en la "colonización" de las periferias por parte de los desarrolladores de urbanizaciones cerradas: haciendo referencia a la frontera urbano-rural, es muy común el recurso a la idea de "llevar la ciudad al campo", para gozar de las comodidades urbanas en un entorno imbuido de una ruralidad idílica y una supuesta alta calidad ambiental (Pintos y Narodowski, 2015).

Lejos de esta ficción - un verdadero "mito"-, las periferias del AMBA son ámbitos de contradicción y disputa entre el capital inmobiliario concentrado y los sectores populares que luchan por el acceso al suelo y a la vivienda. El conflicto desatado en julio de 2020 en el partido de Presidente Perón, entre el Barrio Cerrado San Cirano y la toma de tierras conocida como Barrio Guernica Unido, constituye un excelente ejemplo de ello, y evidencia que detrás de esta tensión se ponen también en juego diferentes modelos de ciudad (Venturini, Ferlicca y Apaolaza, 2020). Recordando que la renta del suelo surge del plusvalor socialmente creado (Jaramillo, 2009), es posible observar cómo las capturas de brechas de renta que han sido analizadas implican una apropiación sumamente desigual e injusta de ese plusvalor social, en un proceso que profundiza la segregación, fragmentación y polarización socio-urbanas de las periferias.

El panorama empeora toda vez que esos cambios en el uso del suelo tienen fuertes impactos ambientales negativos que se externalizan hacia el resto de la comunidad. Este atropello ambiental es muy visible en el caso de la peri rent gap tipo II, generado por la urbanización de humedales, aunque cabe destacar también el potencial que los suelos decapitados tienen para funcionar como "neohumedales", particularmente en el caso 
de Esteban Echeverría. Aquí se ha demostrado la necesidad imperiosa de reservas hídricas en las nacientes de los arroyos (Garay, 2012) que ayuden a prevenir inundaciones como las que afectaron tremendamente a barrios populares del distrito en octubre de 2019.

\section{REFERENCIAS}

Apaolaza, R. (2016). Desplazamiento y periferización popular en el AMBA. Patrones de un modelo urbano excluyente. En WPCC\#163544. Serie IV\#3B. Madrid: Contested Cities. Recuperado de http://contested-cities.net/working-papers/2016/desplazamiento-y-periferizacion-popular-en-el-area-metr opolitana-de-buenos-aires-patrones-de-un-modelo-urbano-excluyente/

Apaolaza, R. (2018). Territorio, transporte y capitales. Dinámicas y efectos del aislamiento socioterritorial sobre los jóvenes residentes de los nuevos asentamientos periféricos del Area Metropolitana de Buenos Aires (Tesis de doctorado en Geografía inédita). Universidad de Buenos Aires, Facultad de Filosofía y Letras. Recuperada de http://reposito rio.filo.uba.ar/handle/filodigital/4586

Bozzano, H. (1998). Reflexiones sobre reestructuración económica, mutaciones productivas y reproductivas en territorios periféricos: el caso de Buenos Aires. En M. Escolar y A. Moraes (Comps.), Los nuevos roles del Estado en el ordenamiento del territorio. Actas del Segundo Seminario Latinoamericano de Geografia Critica (pp. 215-234). Universidad de Buenos Aires, Facultad de Filosofía y Letras.

Ciccolella, P. (2014). Metrópolis latinoamericanas, más allá de la globalización. Buenos Aires: Café de las CiudadesOLACCHI.

Clichevsky, N. (2003). La cuestión urbana en los noventa en la RMBA. Buenos Aires: Instituto del Conurbano Universidad Nacional de General Sarmiento.

Correa, R. (1993). O Espaço Urbano. São Paulo: Atica.

Denuncian emprendimientos ilegales en Canning (19 de septiembre de 2015). El Diario Sur. Recuperado de https:// www.eldiariosur.com/canning/sociedad/2015/9/19/denuncian-emprendimientos-ilegales-canning-n2187.

Garay, A. (2012). Plan Estratégico para el Desarrollo Territorial del Partido de Esteban Echeverría de la Provincia de Buenos Aires (Informe Final Consolidado). Recuperado de https://www.mininterior.gob.ar/planificacion/pdf/ planes-loc/BUENOSAIRES/Plan-Estrategico-Desarrollo-Territorial-del-Partido-de-Esteban-Echeverria.pdf

Gobierno de la Provincia de Buenos Aires (GPBA). (2016). Proyecciones depoblación por Municipio provincia de Buenos Aires 2010-2025. La Plata: Ministerio de Economía, Subsecretaría de Coordinación Económica, Dirección Provincial de Estadística. Recuperado de http://estadistica.ec.gba.gov.ar/dpe/images/Proyecciones_X_municip io__2010-2025.pdf

Guevara, T. (2014). Transformaciones territoriales en la Región Metropolitana de Buenos Aires y reconfiguración del régimen de acumulación en la década neo-desarrollista. Quid 16, (4), 115-136. Recuperado de https://publicac iones.sociales.uba.ar/index.php/quid16/article/view/1155

Guevara, T. (2015). Abordajes teóricos sobre las transformaciones sociales, económicas y territoriales en las ciudades latinoamericanas contemporáneas. Eure, 41(124), 5-24. Recuperado de http://www.eure.cl/index.php/eure/a rticle/view/708/824

Instituto Nacional de Estadística y Censos (INDEC). (2001) Censo Nacional de Población Hogares y Vivienda 2001. Buenos Aires: Autor.

Instituto Nacional de Estadística y Censos (INDEC). (2010) Censo Nacional de Población Hogares y Vivienda 2010. Buenos Aires: Autor.

Janoschka, M. (2002). El nuevo modelo de la ciudad latinoamericana: fragmentación y privatización. EURE, 18(85), 11-29. Recuperado de https://scielo.conicyt.cl/scielo.php?script=sci_arttext\&pid=S0250-7161200200850000 2

Jaramillo, S. (2009). Hacia una teoría de la renta del suelo urbano (2da ed. rev.). Bogotá: Ediciones Uniandes. 
Lanfranchi, G., Cordara, C., Duarte, J. I., Gimenez Hutton,T.; Rodriguez, S. y Ferlicca, F. (2018). ¿Cómo crecen las ciudades argentinas? Estudio de la expansión urbana de los 33 grandes aglomerados. Buenos Aires: CIPPEC. Recuperado de http://www.cippec.org

Morello, J. y Rodríguez, A. (2001). Funciones educativas de las manchas de naturaleza en las ciudades y sus bordes: El caso de Buenos Aires. Texto inédito del Grupo de Ecología del Paisaje y Medio Ambiente (GEPAMA) de la Universidad de Buenos Aires. Recuperado de http://www.gepama.com.ar/morello/downloads/Reservas\%20u rbanas.pdf

Narodowski, P. y Panigo, D. (2015). Proyectos inmobiliarios y proyectos alternativos en humedales. Un ejercicio de rentabilidades comparadas. En P. Pintos y P. Narodowski (Coords.), La privatopía sacrilega. Efectos del urbanismo privado en humedales de la cuenca baja del rio Luján (pp. 157-166). Buenos Aires: Imago Mundi.

Pintos, P. y Narodowski, P. (Coords.) (2015). La privatopia sacrílega. Efectos del urbanismo privado en la cuenca baja del rio Luján. Buenos Aires: Imago Mundi.

Pírez, P. (1994) Buenos Aires metropolitana. Política y gestión de la ciudad. Buenos Aires: Centro Editor de América Latina.

Pírez, P. (2006). La privatización de la expansión metropolitana en Buenos Aires. Economía, Sociedad y Territorio, 6(21), 31-54. Recuperado de https://www.redalyc.org/pdf/111/11162103.pdf

Smith, N. (1979). Toward a Theory of Gentrification A Back to the City Movement by Capital, not People. Journal of the American Planning Association, 45(4), 538-548. https://doi.org/10.1080/01944367908977002

Smith, N. (2012) [1996]. La nueva frontera urbana. Ciudad revanchista y gentrificación. Madrid: Traficantes de Sueños. Recuperado de https://www.traficantes.net/sites/default/files/pdfs/La\%20nueva\%20frontera\%20urbana-TdS .pdf

Stone, C. (1993). Urban Regimes and the capacity to govern: A political economy approach.Journal of Urban Affairs, 15(1), 1-28. https://doi.org/10.1111/j.1467-9906.1993.tb00300.x

Stone, C. (2001). The Atlanta Experience Re-Examined: The Link between Agenda and Regime Change. International Journal of Urban and Regional Research, 25(1), 20-34. https://doi.org/10.1111/1468-2427.00295

Torres, H. (1993). El mapa social de Buenos Aires: 1940-1990. Bs. As.: Universidad de Buenos Aires, Facultad de Arquitectura, Diseño y Urbanismo.

Venturini, J. P., Ferlicca, F. y Apaolaza, R. (26 de septiembre de 2020). La ciudad que se pierde: autopistas, countries y desalojos... Revista Ignorantes. Recuperado de https://rededitorial.com.ar/revistaignorantes/especial-guernica/

\section{Notas}

1 Se entiende el AMBA como el conjunto de la Ciudad Autónoma de Buenos Aires y 31 municipios de la provincia de Buenos Aires sobre los cuales se extiende la aglomeración (Pírez, 1994), a saber: primera corona: Avellaneda, General San Martín, Hurlingham, Ituzaingó, Lanús, Lomas de Zamora, Morón, Quilmes, San Isidro, Tres de Febrero, Vicente López y la primera franja de La Matanza; segunda corona: Almirante Brown, Berazategui, Esteban Echeverría, Ezeiza, Florencio Varela, José C. Paz, Malvinas Argentinas, Merlo, Moreno, San Fernando, San Miguel, Tigre y la segunda franja de La Matanza; tercera corona: Escobar, General Rodríguez, Marcos Paz, Pilar, Presidente Perón, San Vicente y la primera franja de Cañuelas.

2 Para los suelos decapitados es probable que tanto la cantidad de emprendimientos como las superficies involucradas sean mucho mayores, ya que con la metodología de teledetección empleada no es posible identificar suelos que hayan sido afectados por actividades extractivas con mucha anterioridad a los años 2000.

3 El partido de Ezeiza se creó en 1994 con tierras que pertenecían al partido de Esteban Echeverría y la localidad de Canning quedó entonces dividida entre ambos municipios.

4 La notable baja en estas cifras se debe, por un lado, a que los primeros datos incluyen superficie hoy perteneciente al partido de Ezeiza y, por otro, al recambio de usos acaecido sobre los suelos decapitados a lo largo del tiempo.

5 Sobre la relación contradictoria entre urbanización y normativa puede mencionarse como ejemplo el emprendimiento de barrio cerrado "Campos de La Victoria”, en el partido de Esteban Echeverría, donde comenzó la venta de lotes en 2011 sin tener las habilitaciones ni permisos correspondientes. A pesar de la clausura por parte del Municipio en 2014, la 
empresa BEO Group S.A. siguió ofreciendo lotes e incluso comenzó a planificar una segunda parte del emprendimiento en terrenos aledaños ("Denuncian emprendimientos ilegales en Canning", 2015).

6 A pesar de los amplios márgenes de ganancia que reportan, esta compleja relación entre valorización y desvalorización hace que en determinadas zonas las urbanizaciones cerradas no dejen de ser operaciones riesgosas. En Esteban Echeverría, por ejemplo, se observan varios proyectos que han sido abandonados. 